\title{
Effect of time and frequency of static stretching on flexibility of rectus femoris muscle of human subjects
}

\author{
Pooja Chaudhuri ${ }^{1}$ and Nilo. Z. Kiba ${ }^{2}$ \\ ${ }^{1}$ Research Scholar, Department of Physiotherapy, Shri Jagdishprasad Jhabarmal Tibrewala University, Churela \\ Rajasthan \\ ${ }^{2}$ Assistant Professor, Department of Physical Medicine and Rehabilitation, Composite Regional Centre, \\ Guwahati Assam
}

\begin{abstract}
The main aim of present study is to evaluate and compare the effect of frequencies and durations of static stretching on flexibility of rectus femoris muscle of human subjects. A sample of 50 volunteers having tightness of rectus femoris muscle was randomly allocated into five groups. Static stretching of rectus femoris muscle was performed in five different frequency and durations for 6 weeks. Group A $(n=10)$ was subjected to 3 stretches for 30 seconds each once for 5 days in a week for 6 weeks. Group B $(n=10)$ was given 3 stretches for 15 seconds each for 6 weeks. Group C $(n=10)$ was given 1 stretch for 30 seconds. Group D $(n=10)$ was given 1 stretch for 15 seconds. Group E ( $n=10$ ) was given no stretch. The findings revealed that there was statistically significant increase in ROM(knee flexion)in first four groups A,B,C and D except Group E following the treatment with different parameters of time and frequency of static stretching during 6 weeks with mean difference $=6.60$ (pre-interventionmean value \& S.D of ROM=125.80 $\pm 3.645 \mathrm{Et}$ post-intervention mean $=132.40 \pm 3.502$ ), mean difference $=3.60$ (pre-intervention mean $=125.60 \pm 3.718$ \&t post-intervention mean $=129.20 \pm 3.718$ ), mean difference $=6.40$ (pre-intervention mean $=125.20 \pm 4.104$ \& post-intervention mean $=131.60 \pm 4.006$ ), mean difference $=3.60$ (pre-intervention mean $=126.30 \pm 3.773$ \&t post-intervention mean $=129.90 \pm 3.479)$ \&t mean difference $=$ 0.60 (pre-intervention mean $=125.10 \pm 3.784$ \&t post-intervention mean $=125.70 \pm 3.561$ ) respectively. Hence, the study exhibited stretching of rectus femoris muscle three or once for 30 seconds appears to be effective and showed significant improvement compared to 3 or 1 stretch for 15 seconds or no stretching. The results of Tukey test indicated that there is no significant difference between 1 stretch or 3 stretch for 30 second. The results of the present study showed that a one 30 -second duration is an effective amount of time to sustain a rectus femoris muscle stretch in order to increase ROM. No increase in flexibility occurred when the frequency of stretching was increased from one to three times per day.
\end{abstract}

KEY WORDS: FLEXIBILITY, RECTUS FEMORIS MUSCLE, STATIC STRETCHING, MUSCLE PERFORMANCE

\section{ARTICLE INFORMATION:}

*Corresponding Author: dr.poojachaudhuri@gmail.com Received $1^{\text {st }}$ July, 2018

Accepted after revision $25^{\text {th }}$ Sep, 2018

BBRC Print ISSN: 0974-6455

Online ISSN: 2321-4007 CODEN: USA BBRCBA

\%:\% Thomson Reuters ISI ESC / Clarivate Analytics USA and

Crossref Indexed Journal

NAAS Journal Score 2018: 4.31 SJIF 2017: 4.196

$\odot$ A Society of Science and Nature Publication, Bhopal India 2018. All rights reserved.

Online Contents Available at: http//www.bbrc.in/

DOI: $10.21786 / \mathrm{bbrc} / 11.3 / 23$ 


\section{INTRODUCTION}

Flexibility is defined as "the ability of a muscle to lengthen, allowing one joint (or more than one joint in a series) to move through a range of motion (ROM) (Bandy et al., 1994,1998) Roberts et al 1999) and a loss of muscle flexibility as " a decrease in the ability of the muscle to deform," resulting in decreased ROM about a joint. (Bandy et al., 1997, Russell et al., 2004). It is believed that stretching can prevent injury (Zachezewski et al.,1989 Hubley et al., 1984) enhance athletic performance (Anderson et al., 1991,. Beaulieu et al., 1981, Worrell 1994) and assist in rehabilitation following musculoskeletal injury (Agre et al.,1985). Stretching is traditionally used as part of warm up to improve flexibility (Shellock et al., 1985, McMillian et al 2006, Dalrymple et al 2010, Page 2012).

The literature document three methods of stretching exercises to increase flexibility: ballistic stretching, static stretching and PNF techniques. All three methods have been documented to increase ROM immediately after stretching. (Russell et al., 2004, Sady et al 1982). Proprioceptive neuromuscular facilitation involves the use of brief isometric contractions of the muscle to be stretched before statically stretching the muscle. This technique not only requires expertise to perform but also requires one-on-one intervention with another experienced individual. Static stretching is performed by placing muscles at their greatest possible length and holding that position for a period of time (Beaulieu et al., 1981, Anderson et al., 1991,Russell et al., 2004). Ballistic stretch uses bouncing or jerking movements imposed on the muscles to be stretched. The quick, jerking motion that occurs during the ballistic stretch can theoretically exceed the extensibility limits of the muscle in an uncontrolled manner and cause injury. The use of ballistic technique, therefore, has not been widely supported in the literature (Ferreira et al, 2007 \&t Torres et al, 2008).

Although documentation exists that static, ballistic, and PNF techniques will increase the flexibility of muscle, (Sady et al., 1982, Moore et al., 1980), but the most widely used method for increasing ROM because of the simplicity of execution and lower potential for tissue trauma. An ample volume of literature has focused on the effects of stretching on the flexibility of the hamstrings muscle. However,there is a scarcity of evidence of stretching on other muscle groups, such as the gastrocnemius, soleus, quadriceps and triceps surae, (Bandy et al., 1997, Russell et al., 2004). Rectus femoris is the only muscle in the quadriceps group that is involved in hip flexion, since it originates in the pelvis and not the femur. Isolated rectus femoris (RFM) tightness is associated with a variety of clinical disorders. Rectus femoris tightness may lead to alteration in swing phase, increased energy expenditure and pain during walking downstairs or when wearing high heels, ( Csink et al., 1963, Lenart et al., 1974, Lateur et al., 1978 Richard et al., 1985).

Another important point of consideration in the present study is the effect of time and duration of stretching on flexibility of rectus femoris muscle. The duration and frequency of muscle stretching may interfere with the improvement of flexibility. While the literature is unanimous in its support for static stretching resulting in increased ROM, no consistency is apparent with regard to how long stretches (time) and how much stretches (frequency) should be held to obtain optimum benefits. Some researchers suggested that the $30 \mathrm{~s}$ duration of stretching with one or three times a day is effective for increasing muscle flexibility (Marques et al., 2009). However, other studies recommended that the duration of stretching in flexibility training programmers range from 5 to 60 seconds,yet justifications for these selections have largely been absent (Roberts et al., 1999)

The purpose of study was to determine the time and frequency of static stretching that most effectively increase flexibility of the rectus femoris muscles, as measured by active knee flexion test.The effects of five daily frequencies and durations of static stretching on rectus femoris muscle flexibility was compared 5 days per week for 6 weeks: (1) three 15 - second stretches (2) one 30 - second stretch (3) one 15- second stretch (4) a control (no stretching activity).The main objective of this work was to determine the optimal time and frequency of static stretching to increase flexibility of rectus femoris muscle, as measured by active knee flexion test.

\section{MATERIALS AND METHODS}

The present study was an experimental study $(3 \times 5$ factorial designs), performed in the Research lab of Department of Physiotherapy at Shri Jagdishprasad Jhabarmal Tibrewala University, Rajasthan. The Institutional Ethical Committee approved the study, where prior to participation in the study, subjects were explained about the procedures that they would have to follow during the study. The patients' consent was taken on the consent form for participation in the study. All the subjects were the residents of Rajasthan, who volunteered for the study and were randomly allocated into five groups. The size of the sample was 50 subjects with 10 samples each in group A,B,C,D and E. Subjects of either genderaged20 to 30 years having unilateral (right side) tightness of rectus femoris muscle with no history ofback pain, urinary tract infection, soft tissue injury, fracture of lower limb, inflammatory joint $\&$ arthritic condition of lower limb with acute or chronic rectus femoris injury were 
recruited. The subjects must exhibit positive knee flexion test with positive knee flexion ROM between 120$130 \pm 2$ degree. In addition, subjects should not have involved in any lower extremity stretching exercises during 6 week study. The list of variables include time and frequency of static stretching, flexibility of rectus femoris. Universal goniometer with a double - armed, full - circle protractor made of metal was used for all measurements. Rectus femoris muscle flexibility using active knee flexion test of each subject was measured prior to assignment to groups and the reading for ROM were taken once after 6 weeks of intervention. The subject was placed prone, with both feet off the end of the examination table. The knees were extended and the hips positioned in 0 degrees of flexion, extension, abduction, adduction, and rotation.

The hip was stabilized to maintain the neutral position. The hip was not allowed to flex, a cloth strap was then placed securely across the buttocks to stabilize the hips in extension, when the strap was tightened the subject was instructed to adjust his body to a comfortable prone position, because tightening the strap caused the trunk and hips to rotate. With the hips stabilized in extension and the ankle relaxed in plantarflexion over the edge of the table, the subject was told to slowly bend his knee to the point of "initial resistance". When the end point was reached, the degree reading of knee flexion using universal goniometer was observed and recorded.

Following the initial measurements, subjects were randomly assigned to one of five groups. Subjects assigned to group 1 (6 men, 4 women mean age $=24.70$ years, $\mathrm{SD}=2.60)$ did three 30 seconds static stretches (10 seconds between stretches) of the rectus femoris muscle. Group 2 (6 men, 4 women mean age $=24.30$ years, SD $=3.12$ ) did three 15 second static stretches, with a 10 second rest between stretches. Group 3 (4 men, 6 women mean age $=24.40$ years, $S D=2.79$ ) did one static stretch for 30 seconds. Group 4 (4 men, 6 women mean age $=24.40$ years, $\mathrm{SD}=3.27$ ) did one static stretch for $15 \mathrm{sec}-$ onds. The fifth group ( 6 men, 4 women mean age $=24.50$ years, $\mathrm{SD}=2.87$ ) served as a control group and did no stretching activities.

Subjects in group 1 through 4 stretched 5 days a week for 6 weeks.To stretch the rectus femoris muscle, each subject stood upright with one hand against a wall for balance under supervision of the therapist. The knee was flexed and the hip extended, the lumbar spine and pelvis were aligned in a neutral position. The pelvis did not tilt anteriorly nor the low back hyperextend; the hip was not abducted or remained flexed. When the subject did self- stretching, the trunk was erect,not slumped. the subject then flexed the dominant leg to a knee joint angle as possible. and the stop watch was used to calculate the accurate timing (30,15 and $10 \mathrm{sec})$.
After that all subjects were retested after 6 weeks using same procedures described for the pretest.

\section{RESULTS AND DISCUSSION}

The results have been explained under the following sub-headings: 1) Effect of static stretching on flexibility of rectus femoris muscle in term of ROM (knee flexion) with different parameters of time and frequency during 6 weeks:

The primary objective of the current study was to investigate the effect of time and frequency with different parameters of static stretching on the flexibility of rectus femoris muscle. Therefore 4 different parameters of static stretching were administered for the duration of six weeks, namely 3 stretches for 30 seconds, 3 stretches for 15 seconds, 1 stretch for 30 seconds and 1 stretch for 15 seconds once for 5 days in a week. The findings revealed that except the control group, all the four groups showed statistically significant improvement in muscle flexibility.

Stretching the rectus femoris muscle at 3 or 1 stretch for 30 seconds appeared to be effective and showed significant improvement compared to 3 or 1 stretch for 15 seconds or no stretching (control). As indicated by the Tukey test,there is no significant difference between 1 stretch or 3 stretch for 30 seconds. Therefore, 1 stretch for 30 second is a sufficient stretch to increase the flexibility of rectus femoris muscle. The results of this study are consistent with the results of another study conducted by Bandy et al., 1994 comparing the effect of time and frequency with different parameters of static stretching on hamstring muscles, in which stretching for 30 second one or three times per day for 5 days per week for 6 weeks was more effective for increasing muscle flexibility than no stretching. There was no difference between stretching one or three times per day using either a 30 - or 60 - second duration of stretching. The use of longer duration and more frequent daily stretching, therefore must be questioned.

Gains in flexibility involve biomechanical,neurological and molecular mechanisms that determine myofibrillogenesis as a long-term result.The gains in flexibility can also be associated with increased tolerance to pain and increased viscous elastic properties of the muscle-tendon units. Several studies have reported flexibility and ROM after stretching programs and the present results support these findings.The results of this study,in conjunction with previous research ,showed that the increased the duration and frequency beyond one 30 -second stretch performed one time per day did not increase flexibility and it indicated that 30 seconds is an effective length of time to sustain a rectus femoris muscle stretch in 


\begin{tabular}{|c|c|c|c|c|c|}
\hline Groups & A $(n=10)$ & $B(n=10)$ & $C(n=10)$ & $D(n=10)$ & $E(n=10)$ \\
\hline & Mean \pm SD & Mean \pm SD & $\operatorname{Mean}_{ \pm} \mathrm{SD}$ & Mean \pm SD & Mean $_{ \pm}$SD \\
\hline Pre- values & $125.80 \pm 3.645$ & $125.60 \pm 3.718$ & $125.20 \pm 4.104$ & $126.30 \pm 3.773$ & $125.10 \pm 3.784$ \\
\hline Post-values & $132.40 \pm 3.502$ & $129.20 \pm 3.718$ & $131.60 \pm 4.006$ & $129.90 \pm 3.479$ & $125.70 \pm 3.561$ \\
\hline Mean difference & 6.60 & 3.60 & 6.40 & 3.60 & 0.60 \\
\hline
\end{tabular}

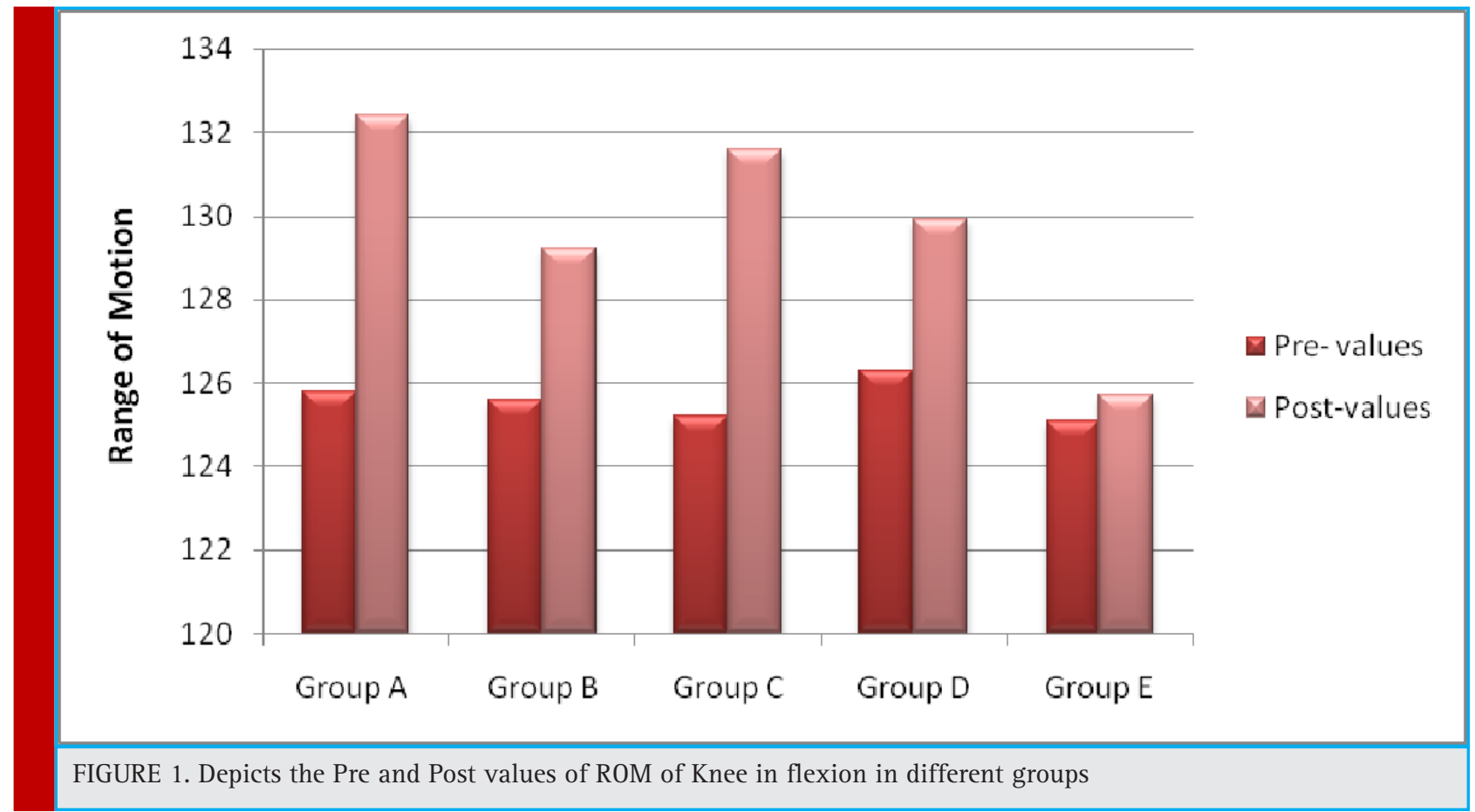

\begin{tabular}{|l|l|l|l|l|l|l|}
\hline Table 2. ANOVA analysis of ROM (knee flexion) for all five groups. \\
\hline Variable & Sources of Variation & SS & Df & MS & F-ratio & Significance \\
\hline \multirow{2}{*}{ Range of motion (ROM) } & Between & 242.72 & 4 & 60.68 & \multirow{2}{*}{195.0429} & \multirow{2}{*}{ Significant } \\
\cline { 2 - 8 } & Within & 14 & 45 & 0.311111 & & \\
\hline
\end{tabular}

order to increase ROM.This observation is clinically relevant,suggesting that one 30 -second stretch performed five times a week is sufficient to improve flexibility compared to stretching at a higher frequency.

This study contrasts with the findings of Bandy and Irion (1998) who found stretching durations of 30 and 60 seconds to be more effective than 15 seconds. However, in the study of Bandy and Irionthere is no indication whether total amount of time spent in a stretch position during the entire training programme was controlled. This factor, if not controlled, could explain the differences observed subjects in the longer duration treatment groups would be exposed to more time in a stretched position and therefore likely to show greater improvements. The present study did control the total amount of time spent in a stretched position during the entire training programme.a stretching duration of 15 seconds resulted in significantly smaller improvements in active ROM than a duration of 30 seconds, suggesting that 15 seconds may not be long enough to elicit a Golgi tendon organ response.

\begin{tabular}{|c|c|c|c|}
\hline & A & & \\
\hline B & Significant & B & \\
\hline $\mathrm{C}$ & Non-Significant & Significant & C \\
\hline
\end{tabular}


Another study of Bandy et al showed that 30-second static stretch performed one time per day over a 6 week period resulted in more than twice the gains in hamstring flexibility than performing dynamic range of motion at the same frequency and duration. Only few of the studies have been done on the flexibility of rectus femoris. Therefore, such studies contribute little toward understanding the mechanisms behind the acquired increase in ROM after stretching.

\section{CONCLUSION}

Our study demonstrated that although stretching for 30 seconds one or three times per day for 5 days per week for 6 weeks was more effective for increasing muscle flexibility (as determined by increased knee flexion ROM) than no stretching or $15 \mathrm{sec}$ stretch, there was no difference between one or three times per day using 30 - second duration of stretching. Therefore, 30 - second duration is an effective amount of time to sustain a rectus femoris muscle stretch in order to increase ROM. The results from this study will be helpful for individuals who desire to increase their flexibility in an attempt to decrease injury and enhance performance, as well as for those clinicians who incorporate static stretching activities as part of their rehabilitation programs.

\section{REFERENCES}

Agre JC (1985). Hamstring injuries: Proposed etiological factors, prevention, and treatment. Sports Medicine ; Vol. 2(1): Pages 21-33.

Anderson B, Burke ER (1991). Scientific medical and practical aspects of stretching. Clinics in Sports Medicine; Vol. 10(1): Pages 63-86.

Bandy WD, Irion JM (1997).The effect of time and frequency of static stretching on flexibility of the hamstring muscles. Physical Therapy; Vol. 77(10): Pages 1090-1096.

Bandy WD, Irion JM (1994). The effect of time on static stretch on the flexibility of the hamstringmuscle. Physical Therapy; Vol. 74: Pages 845-850.

Bandy WD, Irion JM (1998). The effect of static stretch and dynamic range of motion training on the flexibility of the hamstrings muscles. Journal of Orthopaedic \& Sports Physical Therapy; Vol. 51: Pages 637-663.

Beaulieu JE (1981). Developing a stretching program. The Physician and Sports Medicine; Vol. 9 (11): Pages 59-65.

Csink L,Imre J (1963). Isolated contracture of the rectus femoris muscle. Clinical Orthopaedics; Vol. 45 B,no 1.

Dalrymple KJ, Davis SE, Dwyer GB, Moir GL. (2010) Effect of static and dynamic stretching on vertical jump performance in collegiate women volleyball players. The Journal of Strength and Conditioning Research; Vol 24(1): Pages 149-15
De Lateur BJ, Stonebridge JB (1978). Fibrous muscular contractures: Treatment with a new direct contact microwave applicator operating at $91 \mathrm{MHz}$. Archives of Physical Medicine and Rehabilitation t; Vol. 59(10): Pages 488-99.

Ferreira GN, Teixeira-Salmela LF, Guimaraes CQ (2007) Gains in flexibility related to measures of muscular performance: impact of flexibility on muscular performance. Clinical Journal of Sport Medicine; Vol.17(4): Pages 276-281

Hubley CL, Kozey. JW (1984). Can stretching prevent athletic injuries? Journal of Musculoskeletal Medicine; Vol. 7(3)19: Pages 25-34.

Jennifer M Roberts, Karen Wilson (1999). Effect of stretching duration on active and passive range of motion in the lower extremity. British Journal of Sports Medicine; Vol. 33(4): Pages 259-263.

Lenart, Kullman (1974) Isolated contracture of the rectus femoris muscle. Clinical Orthopaedic; Vol. 99: Pages 125-130.

Marques AP, Vasconcelos AA (2009). Effect of frequency of static stretching on flexibility, hamstring tightness and electromyographic activity.Brazilian Journal of Medical and Biological Research, Vol. 42(10): Pages 949-53.

McMillian DJ, Moore JH, Hatler BS, Taylor DC. (2006) Dynamic vs. static-stretching warm up: the effect on power and agility performance. The Journal of Strength and Conditioning Research; Vol.20(3):Pages 492-499

Moore M, Hutton R (1980). Electromyographic investigation of muscle stretching techniques. Medicine \& Science in Sports \& Exercise; Vol. 12(5): Pages 322-329.

Page P (2012 ) Current concepts in muscle stretching for exercise and rehabilitation. International journal of sports and physical therapy;Vol 7(1) : Pages 109-119.

Gajdosik R (1985). Rectus femoris muscle tightness: Intratester Reliability of an Active Knee Flexion test Journal of Orthopaedic Et Sports Physical Therapy; Vol. 6(5): Pages 289-292.

Russell T. Nelson, William D. Bandy (2004). Eccentric Training and Static Stretching Improve Hamstring Flexibility of High School Males. Journal of Athletic Training; Vol. 39(3): Pages 254-258.

Sady SP, Wortman M (1982). Flexibility training: ballistic, static or proprioceptive neuromuscular facilitation? Archives of Physical Medicine and Rehabilitation; Vol. 63(6): Pages 261-263.

Shellock FG, Prentice WE (1985). Warming up and stretching for improved physical performance and prevention of sports -related injuries. Sports Medicine; Vol.2 (4): Pages 267-278.

Torres EM, Kraemer WJ, Vingren JL (2008) Effects of stretching on upper-body muscular performance. The Journal of Strength and Conditioning Research; Vol.22(4): Pages 1279-1285

Worrell TW, Smith TL, Winegardener J (1994). Effects of hamstring stretching on hamstring muscle performance.Journal of Orthopedics Sports Physical Therapy; Vol.20(3): Pages 154-159.

Zachezewski JE (1989). Improving flexibility.In:Physical Therapy. Philadelphia, Pa :JB Lippincott Co: Pages 698-699. 